\title{
Studies on Financial Support System of the Construction of the New-type Urbanization in Shanxi Province
}

\author{
Meng Jun \\ Accounting College, Xi'an peihua University, Xi'an, Shaanxi, 710125, China
}

Keywords: New urbanization; Financial support; Financing demand; New urbanization

\begin{abstract}
New urbanization construction is an important engine of China's future economic growth, and it needs all-round financial support and form a complete financial support system. However, due to the lack of financial resources in supporting the construction of new urbanization process there are still many shortcomings and disadvantages, the problem of insufficient supply has become increasingly prominent. Based on the experience of financial support model of urbanization in typical developed countries and the special economic situation of Shaanxi Province, the urbanization construction needs to construct the investment and financing system of "government guidance + market dominance", promote the construction of direct financing mechanism, actively develop the capital market, Innovative investment and financing.
\end{abstract}

\section{Introduction}

The new urbanization is urbanization based on urban and rural integration, conservation, ecological livability and harmonious development. It is the urbanization of the rural population after entering the town and entering the town [1]. Urbanization is the driving force of China's economic growth in the future, and it will become the main focus of the future financial services entity economy. Finance is the core of modern economy, in support and promote urbanization construction, plays an irreplaceable role. With the acceleration of the urbanization process, Shaanxi Province is facing huge financing challenges [2][3]. According to the National Research Center estimates, by 2020 China's urbanization will increase the investment demand of more than 40 trillion, the initial estimate of the financial sector's average annual funding needs of not less than 5 trillion yuan [4]. New urbanization for the financial industry has brought a new round of opportunities and challenges, creating a vast "blue ocean market."

\section{New urbanization development booster}

Urbanization is a dynamic process that requires continuous optimization of the elements to achieve a comprehensive and balanced development process. The richness of financial products, the development of financial institutions [5], the perfection of the financial system and the systematic reduction of the transaction costs in the urban economy, the promotion of the effectiveness of urban investment, the promotion of savings in the process of urbanization, and the development of urbanization. financial support [6]. The process of financial support to the dynamic evolution of urbanization is the process of financial support system to promote the realization of financial function in urbanization. 


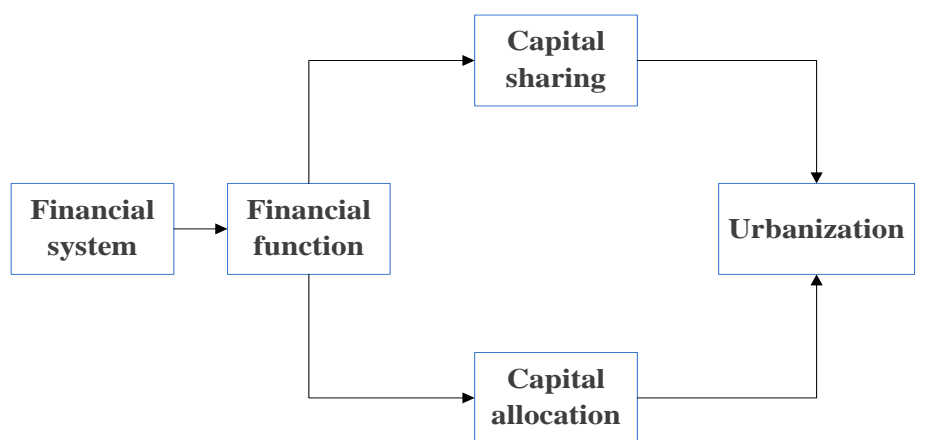

Figure 1. Financial support urbanization evolution mechanism diagram

In the course of the dynamic evolution of urbanization, the financial system under the market-oriented to give full play to their own advantages, through the price advantage and information channels to guide the capital flow of small investment risk and high profit levels in the field, to promote the optimal allocation of capital in different areas, Promote the sustainable development of urbanization.

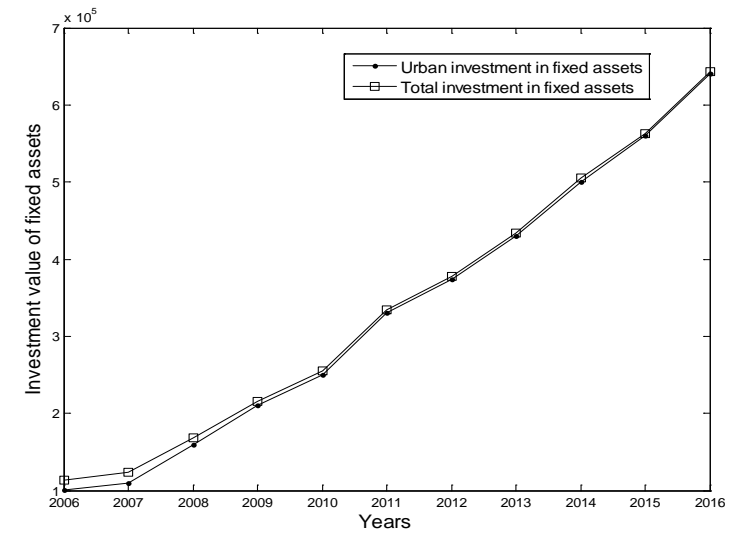

Figure 2. Urban fixed assets and total fixed asset trends from 2006 to 2016

As shown in the figure, in 2006-2016, the scale of urban fixed asset investment and the scale of fixed assets investment in the whole society are basically the same, and the trend is increasing. The proportion of fixed assets investment in urban fixed assets investment is increasing year by year, In 2004, it was only RMB102028.19 billion, accounting for $83.75 \%$ of the total investment in fixed assets [7]. By 2016, the scale of fixed assets investment in urban areas was as high as 436527.7 billion yuan, accounting for $97.64 \%$ of total fixed assets investment [8]. Figure 3 shows that since 2000, the domestic fixed assets investment sources, the use of foreign capital and other sources of funding are in a downward trend, only the amount of self-financing continue to increase from 2000 to $42.5 \%$ To $65.56 \%$ in 2012. This shows that the financial support system has become the main source of external funds for urbanization infrastructure construction in China.

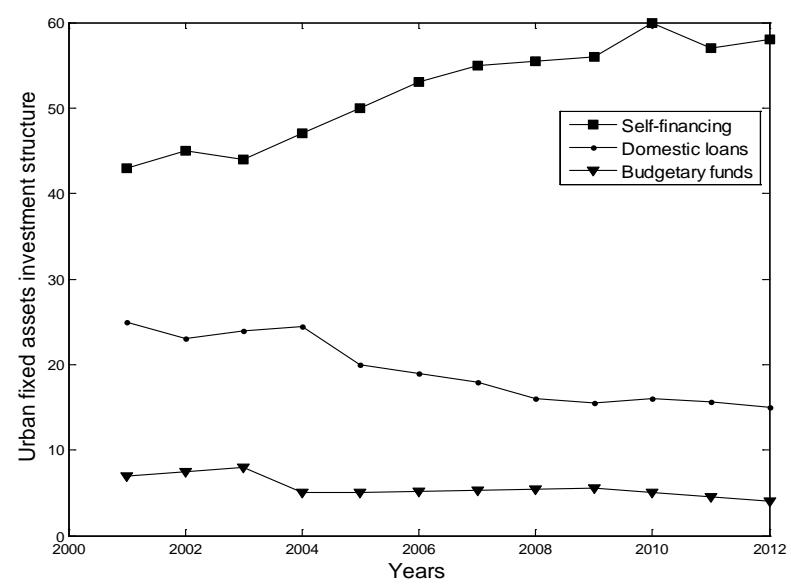

Figure 3. Urban fixed assets investment structure from 2001 to 2012 


\section{Problems Faced by Financial Support in New Urbanization in Shaanxi Province}

According to the "China Urban Development Report (2012)" issued by the Chinese Academy of Social Sciences, there will be 400 million and 500 million farmers in the country in the next 20 years to realize urbanization. If the cost of migrant workers is 100,000 yuan per capita, 40 trillion -50 trillion yuan of huge amounts of money, while the urbanization rate in Shaanxi Province in 2013 is $52.8 \%$, is expected to reach $61 \%$ by 2020 urbanization rate. In 2014, the population of Shaanxi Province was 37.75 million [9]. At the rate of development, the annual investment would need about 33.8 billion yuan, accounting for about $10 \%$ of the total annual revenue of Shaanxi Province (total revenue of Shaanxi province total revenue of 314.492 billion yuan ). Obviously, the huge financial needs of urbanization if the local government financial investment is not enough, but also need a wide range of financing. At present, the urbanization construction funds mainly come from the local finance. In 2014, the distribution of fixed assets investment sources in Shaanxi Province shows that the proportion of funds in the state budget is $6.9 \%$, the proportion of domestic loans is $10.7 \%$, the proportion of bonds is $0.1 \%$, the use of foreign capital accounted for $1 \%$, self-financing 65.9 , other funds accounted for $15.4 \%$ [10]. Through the above data we found that self-financing accounted for a large proportion, while the proportion of bank credit is not high, especially the use of bonds and foreign capital ratio is low. It can be seen that the intensity of financial support for urbanization is far from the financing demand of urbanization, and the financial suppression is mainly manifested in the following aspects.

Insufficient financial support. With the acceleration of the urbanization process, urban infrastructure construction and public services, new agriculture, small and medium-sized enterprise development and farmers' urbanization will generate a lot of financial demand. However, the shortage of funds has become a bottleneck restricting the development of urbanization. First, the infrastructure construction financing channel is single. The infrastructure includes water and electricity, road communication and urban housing and recreational facilities. Because of the characteristics of public welfare, the funds are large, the investment period is long, the recovery is slow and the cost is high, and the commercial banks pursue profitability [11]. Business purpose there is a contradiction. Commercial financial institutions for efficiency, safety, liquidity considerations, more willing to credit funds to the project is good, high technology content, market, and urban infrastructure support small.

Second, the township SME financing difficult problem is more prominent. SME financing costs are too high, the cost of loans in addition to interest, but also to pay registration fees, assessment fees, notary fees, security fees and other costs, the total cost of financing about $15 \%$. Small and medium-sized enterprises themselves financial strength and ability to resist risks is weak, it is difficult through the provision of effective security mortgage, to achieve credit access standards, forcing it to borrow foreign debt and other means to solve the financial difficulties. Capital market in the GEM and the opening of small plates, only to solve less than $1 \%$ of the development of small and medium enterprises need funds, the listing of the harsh conditions lead to the vast majority of small and medium enterprises discouraged.

The imperfect financial system. Financial support The lack of urbanization is mainly reflected in the following aspects:

First, lack of commercial financial support. The financial sector is fighting each other, often using the deposit and loan interest rate market for vicious competition, lack of cooperation spirit, it is difficult to form a financial force to support the rapid and healthy development of urbanization. On the other hand, the convergence of financial institutions is more serious, the commercial banks are keen to grab large enterprises and high-quality customers, and small micro-enterprises, agriculture-related financial services, lack of enthusiasm, especially for small farmers financial services is " Three homes ", leading to the construction of small towns, agricultural industrialization management" no sticks according to ".

Second, the lack of policy-oriented financial institutions. At present, China Agricultural Development Bank, CDB and other policy banks did not play their due role. In China, the 
Agricultural Development Bank has served as the task of providing policy financial support for the development of agriculture, rural areas and farmers. However, the operation mechanism is not perfect, and the problems such as single business and lack of function have long been restricted by the role of agricultural development banks.

Third, small and medium-sized financial institutions to support capacity is limited. Although the development of small and medium-sized financial institutions is relatively fast, the number is more, but its deposit is small, a single financing channels, lack of funds, operational capacity, risk control ability is far less than the state-owned commercial banks, The financial support for the new urbanization construction quality and effectiveness.

Financial support mode. At present, the financial support of urbanization is still too dependent on the traditional bank credit means, through the listing, issuance of bonds and other direct financing share is very low, the financial market level of a single. At the end of 2014, there were 92 enterprises listed in Shaanxi Province, accounting for only 3.5\% of the total listed companies. This kind of single financing system can not meet the requirements of diversification of financial services in the process of urbanization, and the indirect financing-oriented financing structure not only leads to systemic risk accumulation in the banking system, but also the bank's low risk preference It is difficult to credit resources to the field of urban construction tilt.

Financial Services lag. First, the financial supply structure is not reasonable. From the perspective of financial needs in the process of urbanization, the proportion of "small loans" and "three rural" loans in the current banking supply structure is still small. Second, the financial institutions of credit products mainly to secured mortgage-based, the existing homogeneous financial products and services can not meet the diversification of urbanization in the construction of the financial needs. Third, the financial institutions in the land contract management rights and mortgage, animal husbandry and agricultural products processing, storage and transportation and other financial support did not achieve effective docking, the corresponding financial products rarely, financial services lagged behind the development of urbanization.

\section{Construction of Financial Support System for Urbanization Development}

Urbanization development is a complex system engineering, depends on a full range of financial support, build a "government guidance + market-led" investment and financing system, promote the direct financing mechanism, and actively develop the capital market, innovation and investment financing and other financial support system , Become a new type of urbanization development of the inevitable choice.

Building "government guidance + market-led" investment and financing system. Strengthening the financial support of urbanization is inseparable from the government's regulation and guidance. The establishment of financial funds to support the relevant financing platform and enrich the long-term mechanism of corporate capital to market-oriented way to improve the financing platform for urbanization financing platform. We will actively promote the reform of the rural financial system, relax the restrictions on the access of foreign capital and private capital, construct diversified financial organizations such as small and medium-sized financial support subjects, diversified governance structures and forms of ownership, community banks and other diversified financial organizations to meet the new Urbanization development of the funding needs. Vigorously cultivate private financial institutions, regulate the induction of "underground finance" to become a legitimate investment and financing subjects; so that different financial institutions according to their business objectives and market competition rules, different economic areas to provide the necessary financial support. To financial funds as the guide, and actively guide the social capital into the field of public services, the use of various financing means to raise funds for development. To private funds to form a new urbanization development and construction funds, with financial funds as a guide to attract social corporate investment. 


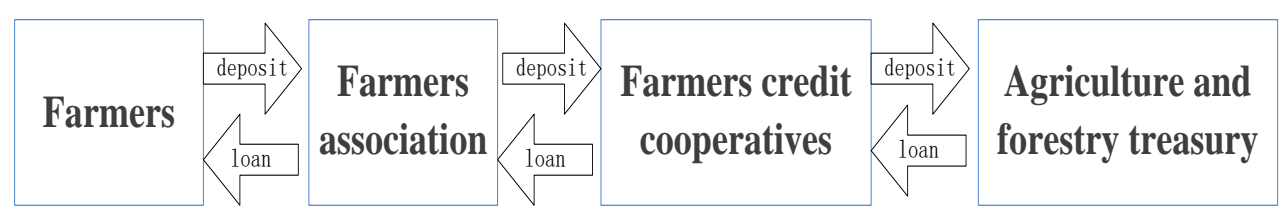

Figure 4. Structure of three - level agricultural association

Innovative investment and financing. Urbanization development of equity capital investment demand, to debt, borrow the main way of financing difficult to follow, should actively explore the means of financing for urbanization. Development of property rights trading center, the higher credit rating of the leading enterprises to actively promote its listed on the motherboard, the GEM listed on the conditions of SMEs to promote the issuance of small and medium-sized enterprises to set the notes and regional gifted notes financing, the quality of enterprises are encouraged It is through the listing, issuing bonds to broaden the financing channels. Rationalize the development of government and financing platform, timely expansion of local government independent debt pilot to reduce the local government financing costs, enhance the local government financial arrangements.

\section{Summary}

Financial system as a modern economic development of the lubricant is to support the construction of Shaanxi Province. The current financial sector to support urbanization, both a business opportunity, but also a challenge, faced with many problems and difficulties. Only by reform and innovation, the financial sector can solve new problems and contradictions in order to realize the win-win goal of urbanization and financial industry mutual promotion and common development.

\section{Acknowledgement}

This work was supported by Shaanxi Province social science sector 2017 major theoretical and practical issues research project "Shaanxi Province new urbanization financing system research", subject number: 2017C068, project leader: Meng Jun.

\section{References}

[1] Ma X, Zhang Z P, Liu Y. Reflections on the Construction of the New Urbanization in Shanxi[J]. Applied Mechanics \& Materials, 2014, 641-642:550-555.

[2] Li N. The research on financial support of new type of urbanizition in Shanxi Province[J]. Journal of Shanxi Agricultural University, 2016.

[3] Liu L, Yun N, Zhang Y. Research on Policy Financial Supporting New-type Urbanization Construction based on the Grey Correlation Model[J]. Journal of Regional Financial Research, 2016.

[4] Geng C H. Path Research of the Construction of the New Type of Urbanization by Finance Support of Jilin Province[J]. Journal of Changchun Finance College, 2016.

[5] Zhang L, Magazine T. On the construction of new-type urbanization in China under the perspective of "Four Comprehensives" strategic thought[J]. Journal of Shanxi Agricultural University, 2016.

[6] Yang H, Peng-Fei N I. Study on the Financial Support to New-type Urbanization-From the Perspective of Coordinated Development[J]. Journal of Shanxi University of Finance \& Economics, 2015.

[7] Jin-Hua J U, Zhi-Qiang J I. A Study of Urbanization Construction and Reform of the Rural Vocational Education in Shanxi[J]. Academic Journal of Jinyang, 2005. 
[8] He G, Lu Y, Li L. Study on Financial Policy of Promoting New-type Urbanization and Balancing Urban and Rural Development_-Taking Xindu District of Chengdu as an Example[J]. China Ancient City, 2015.

[9] Gao Y. Reflections on Rural Land Circulation Problem under the Background of New-type Urbanization in China[J]. Journal of Shanxi Agricultural Sciences, 2016.

[10] Xiao G. Research on the evaluation index system of new urbanization for Jilin Province[J]. Journal of Shanxi Agricultural University, 2016.

[11] Wang S. Research on the innovation of social governance of grass roots under the background of new urbanization[J]. Journal of Shanxi Agricultural University, 2016. 